\title{
Ionic Liquid-Multiwalled Carbon Nanotubes Nanocomposite Based All Solid State Ion-Selective Electrode for the Determination of Copper in Water Samples
}

\author{
Cecylia Wardak *(1), Karolina Pietrzak (1) and Małgorzata Grabarczyk \\ Department of Analytical Chemistry, Institute of Chemical Sciences, Faculty of Chemistry, \\ Maria Curie-Sklodowska University, Maria Curie-Sklodowska Sq. 3, 20-031 Lublin, Poland; \\ karolina.pietrzak@poczta.umcs.lublin.pl (K.P.); malgorzata.grabarczyk@mail.umcs.pl (M.G.) \\ * Correspondence: cecylia.wardak@mail.umcs.pl
}

check for updates

Citation: Wardak, C.; Pietrzak, K.; Grabarczyk, M. Ionic Liquid-

Multiwalled Carbon Nanotubes

Nanocomposite Based All Solid State Ion-Selective Electrode for the Determination of Copper in Water Samples. Water 2021, 13, 2869. https://doi.org/10.3390/w13202869

Academic Editors: Barbara Leśniewska and Julita Malejko

Received: 30 July 2021

Accepted: 12 October 2021

Published: 14 October 2021

Publisher's Note: MDPI stays neutral with regard to jurisdictional claims in published maps and institutional affiliations.

Copyright: (c) 2021 by the authors. Licensee MDPI, Basel, Switzerland. This article is an open access article distributed under the terms and conditions of the Creative Commons Attribution (CC BY) license (https:/ / creativecommons.org/licenses/by/ $4.0 /)$.

\begin{abstract}
A new copper sensitive all solid-state ion-selective electrode was prepared using multiwalled carbon nanotubes-ionic liquid (1-butyl-3-methylimidazolium hexafluorophosphate) nanocomposite as an additional membrane component. The effect of nanocomposite content in the membrane on the electrode parameters was investigated. The study compares, among others, detection limits, sensitivity, and the linearity ranges of calibration curves. Content $6 \mathrm{wt}$ \% was considered optimal for obtaining an electrode with a Nernstian response of $29.8 \mathrm{mV} /$ decade. An electrode with an optimal nanocomposite content in the membrane showed a lower limit of detection, a wider linear range and $\mathrm{pH}$ range, as well as better selectivity and potential stability compared to the unmodified electrode. It was successfully applied for copper determination in real water samples.
\end{abstract}

Keywords: copper ion-selective electrode; solid contact; nanocomposite; potentiometry; copper determination

\section{Introduction}

Copper occurs naturally in metallic form, as well as in ores and minerals, and in the form of complexes and solid particles in various types of water: surface, drinking, ground and sea water $[1,2]$. Due to its many useful properties, which include: high stability, flexibility and electrical conductivity, both copper and its numerous alloys have many applications in households and industry (in electroplating and photography, microelectronics, or as catalysts) [1]. Copper is an important trace element necessary for the proper functioning of human and animal organisms, however, both the excess and deficiency of this element can cause adverse health effects [1].

Copper is, inter alia, a component of metalloenzymes in which it acts as an electron donor or acceptor in important redox reactions, including collagen cross-linking, melamine production or mitochondrial respiration. Its presence makes it possible to maintain homeostasis and the proper functioning of the body from the development and growth of the fetus. Copper plays an important role in the metabolism of iron and glucose, helps in the proper work of the brain and heart muscle. It takes part in the synthesis of neurotransmitters as well as in antioxidant and immunological processes [1,3,4]. Long-term exposure to overly high concentrations of copper can cause many health problems [5]. A high concentration of copper can lead to redox reactions of the Fenton type, and hence to oxidative damage to biological systems, and cell death [3]. Copper is indirectly associated with the occurrence of neurological disorders, including prion diseases or Alzheimer's disease [1]. People who consciously or unknowingly ingest increased doses of copper develop a number of symptoms including dizziness and nausea, headache and abdominal pain, diarrhea and vomiting, irritation of the eyes, nose and mouth. In such a situation, liver and kidney failure and, in severe cases, even death can occur [1,5]. 
The human body contains about $100 \mathrm{mg}$ of copper, while the recommended daily intake of copper is about $2 \mathrm{mg}$, and a dose of $10-15 \mathrm{mg}$ is considered toxic [2,3]. Copper enters the human body with food and drinking water [1]. Foods that are rich in copper include nuts, grains, legumes, potatoes and some fruits, as well as the liver of mammals, molluscs and crustaceans [1]. Depending on many factors, the copper content of drinking water may range from 0.005 to $30 \mathrm{mg} \mathrm{L}^{-1}$ [2]. The heavy metal content of the aquatic environment has increased in parallel with the rapid industrialization over the past 150 years. The average concentration of copper in uncontaminated river waters is $10 \mu \mathrm{g} \mathrm{L}^{-1}$ and in polluted waters it can reach $30-60 \mu \mathrm{g} \mathrm{L}^{-1}$. In recreational reservoirs, concentrations of $1 \mathrm{mg} \mathrm{L}^{-1}$ and lower are used to suppress the growth of harmful algae. Taking into account both the beneficial and toxic effects of copper, its monitoring in the environment is very important. In water samples copper can be easy determined potentiometrically using a copper ion-selective electrode.

Potentiometry is one of the simpler analytical techniques using easy-to-use apparatus, and is also characterized by relatively low costs and speed of measurements $[6,7]$. Thanks to these advantages, potentiometry is used to determine more than 60 different analytes in many branches of science and industry (chemical and clinical analysis, environmental monitoring, process control, etc.) $[7,8]$. Potentiometric measurement consists of measuring the electromotive force of a cell working under near-zero current conditions consisting of a working electrode, which is an ion-selective electrode, and a reference electrode [8].

In the last decades, ion-selective electrodes with solid contact have gained great popularity, in which the liquid contact is replaced only by an additional thin layer of a substance characterized by ionic and electronic conductivity, placed between the electrode material and the membrane layer. This was made to improve the stability and reproducibility of the electrode potential, which deteriorated significantly when the ion-selective membrane was applied directly to the surface of the solid electrode, as was the case with coated wire electrodes, first proposed almost 50 years ago. By eliminating the internal solution, the electrodes were designed to be smaller in size, easier to handle and store than their predecessors, and to avoid the risk of solution evaporation or leakage [8]. Ion-selective electrodes with solid contacts are also characterized by an easier structure than their classic predecessors, with greater possibilities of shape modification and lower production costs. Moreover, these types of electrodes often allow for lower detection limits and can work in any position and under unfavorable conditions (e.g., high pressure), in which sensors of other types could be damaged [2,9].

In recent years, many electroactive substances have been used as solid contacts in ion-selective electrodes: conducting polymers (typically polypyrrole doped by chloride ions [10], ladder conjugated polymer-thieno[3,2-b]thiophene [11]), hydrogel [12], redoxactive self-assembled monolayers [13], carbon nanomaterials (singlewalled carbon nanotubes (SWCNTs) and graphene [14], multiwalled carbon nanotubes (MWCNT) [15] colloidimprinted mesoporous carbon [16], three-dimensionally ordered macroporous (3DOM) carbon [17], carbon black [18]), nanoparticles (gold [19] and platinum [20]). To achieve better properties of analytical sensors, scientists have also used combinations of several components used for this purpose (multiwalled carbon nanotubes and bimetallic nanoparticles $\mathrm{AuCu}$ [21]) or their modifications (gold nanoparticles functionalised with lipoic acid or lipoic amide [22] or octadecane modified MWCNT [23]).

In this work, a new all solid-state copper ion selective electrode based on multiwalled carbon nanotubes-ionic liquid nanocomposite is described. A nanocomposite was prepared using multiwalled carbon nanotubes and 1-butyl-3-methylimidazolium hexafluorophosphate $\left(\mathrm{BMImPF}_{6}\right)$. Both components play an important role in the electrode operation and contribute to the improvement of its analytical and electrical parameters. Multiwalled carbon nanotubes act as ion-to-electron transducer facilitating the charge transfer between the membrane and the internal electrode [15,24]. As we have shown in previous works, ionic liquids can be successfully used as an ionic membrane component that reduces resistance and facilitates the transport of the main ion from the water phase to the membrane $[25,26]$. 
1-butyl-3-methylimidazolium hexafluorophosphate $\left(\mathrm{BMImPF}_{6}\right)$ was successfully used as an extraction solvent for preconcentration of copper $[27,28]$. Therefore, we have decided to use this ionic liquid in the form of a nanocomposite with MWCNTs to prepare copper all solid-state ion-selective electrodes. The use of a nanocomposite combines the beneficial functions of both components and allows a homogeneous membrane to be obtained.

\section{Materials and Methods}

\subsection{Reagents}

$\mathrm{N}, \mathrm{N}, \mathrm{N}^{\prime}, \mathrm{N}^{\prime}$-Tetracyclohexyl-2,2'-thiodiacetamide (copper(II) ionophore IV) and 2-nitrophenyl octyl ether (NPOE) were purchased from Fluka. Ionic liquid: 1-butyl3-methylimidazolium hexafluorophosphate $\left(\mathrm{BMImPF}_{6}\right)$, multiwalled carbon nanotubes (MWCNTs) with 6-9 nm diameter, $5 \mu \mathrm{m}$ length and poly(vinyl chloride) low molecular weight (PVC) were obtained from Sigma Aldrich. Copper nitrate (pure pro analysis), other nitrate salts used in the interference study and other reagents were purchased from Fluka. All aqueous solutions were prepared using freshly deionized water.

\subsection{Preparation of Nanocomposite}

MWCNTs- $\mathrm{BMImPF}_{6}$ nanocomposite was obtained by mixing $100 \mathrm{mg}$ of nanotubes with $500 \mathrm{mg}$ of ionic liquid and thorough homogenization of the mixture in an ultrasonic bath for $1 \mathrm{~h}$.

\subsection{Preparation of the Electrode}

Electrodes with different nanocomposite contents in the membrane from 0 to $8 \%$, were made. The membranes contained, for electrode 1: $1 \%$ ionophore, $33 \%$ PVC, $66 \%$ NPOE; for electrode 2: $1 \%$ ionophore, 33\% PVC, $64 \% \mathrm{NPOE}, 2 \%$ nanocomposite; for electrode $3: 1 \%$ ionophore, 33\% PVC, $62 \% \mathrm{NPOE}, 4 \%$ nanocomposite; for electrode $4: 1 \%$ ionophore, $33 \%$ PVC, 60\% NPOE, $6 \%$ nanocomposite; for electrode 5: 1\% ionophore, 33\% PVC, $58 \%$ NPOE, $8 \%$ nanocomposite. Membrane components were weighed in appropriate proportions into a glass vial, $1 \mathrm{~mL}$ THF per $0.1 \mathrm{~g}$ of the mixture was added and homogenized in an ultrasonic bath for $30 \mathrm{~min}$, and then applied to the surface of the inner electrode. The mixture prepared in this way is visually homogeneous even after 1 month from preparation. In the case of adding nanotubes to the membrane cocktail, but without an ionic liquid, the sediment of the nanotubes is clearly visible at the bottom of the glass vial already 2 weeks after the preparation.

Glassy carbon disks with $3 \mathrm{~mm}$ diameters were used as the internal electrode. Before covering them with a membrane mixture, they were thoroughly polished with $\mathrm{Al}_{2} \mathrm{O}_{3}$ powder, rinsed with water in an ultrasonic bath and additionally immersed in THF and dried in the air. Next, the membrane was deposited on the electrode surface by drop casting 3 times $30 \mu \mathrm{L}$ of membrane mixture dispersed in THF and left to dry for $24 \mathrm{~h}$. Th next day, the electrode was immersed in $1 \times 10^{-3} \mathrm{~mol} \mathrm{~L}^{-1} \mathrm{Cu}\left(\mathrm{NO}_{3}\right)_{2}$ solution for at least $24 \mathrm{~h}$. The electrode was also stored in such a solution between measurements.

For comparison purposes, a classical electrode with an internal filling solution was prepared and labeled as electrode $1^{*}$. The membrane of this electrode had the same composition as in electrode 1 without the nanocomposite (1\% ionophore, 33\% PVC, 66\% NPOE). It was prepared exactly according to the procedure described previously [29]. A piece of the membrane in the shape of a circle with a diameter of $5 \mathrm{~mm}$ was mounted in a Philips IS 561 electrode body, which was then filled with an internal solution $1 \times 10^{-3} \mathrm{~mol} \mathrm{~L}^{-1}$ $\mathrm{Cu}\left(\mathrm{NO}_{3}\right)_{2}$. Between measurements this electrode was stored in the same solution.

\subsection{The Measurement of the Electromotive Force}

The EMF measurements were performed in the system copper ion-selective electrode as the indicating electrode and a silver-chloride electrode (Metrohm 6.0750.100) as the reference electrode. All measurements were made at room temperature in mixed solutions using a 16-channel data acquisition system (Lawson Labs. Inc., Malvern, PA, USA) coupled 
with a computer. An Orion 81-72 glass electrode connected to a multifunction computer meter CX-741 (Zabrze-Mikulczyce, Poland) was used for pH measurements.

\subsection{Electrochemical Impedance Spectroscopy Measurements}

Electrochemical impedance spectroscopy (EIS) measurements were performed in $1 \times 10^{-2} \mathrm{~mol} \mathrm{~L}^{-1} \mathrm{Cu}\left(\mathrm{NO}_{3}\right)_{2}$ solution using an AUTOLAB electrochemical analyzer (Eco Chemie, Netherlands) controlled by NOVA software. For this purpose, a conventional threeelectrode system was used, in which the working electrode was the tested ion-selective electrode, the auxiliary electrode was a platinum wire, and the reference electrode was an $\mathrm{Ag} / \mathrm{AgCl}$ silver chloride electrode $\left(3 \mathrm{~mol} \mathrm{~L}^{-1} \mathrm{KCl}\right)$. The impedance spectra were recorded in the frequency range $0.1-100 \mathrm{kHz}$ and at open circuit potential using an $\mathrm{AC}$-amplitude of $10 \mathrm{mV}$.

\section{Results and Discussion}

Both ionic liquids and MWCNTs exhibited hydrophobic and electrically conductive properties. These features make them good candidates for the modification of polymer ion selective electrode membranes to improve their electrical and mechanical properties. As we have shown in our previous research on cadmium solid contact ISEs [30], IL and MWCNTs show synergistic properties, which means that an electrode with a membrane containing both of these components shows better performance compared to electrodes whose membranes were modified only with an ionic liquid or only with carbon nanotubes. A similar effect was reported in relation to other electrochemical sensors [31].

It is known that imidazolium based ionic liquid, due to presence of cation- $\pi$, interacts with the $\pi$ electronic surface of the MWCNTs [32]. Due to this, MWCNTs are surrounded by an ionic liquid layer which provides both steric and electrostatic stabilization, and a homogenous composite material is formed. Therefore the MWCNTs-IL nanocomposite can be effectively dispersed in the membrane cocktail without the use of additional dispersing agents.

\subsection{Potential Response}

The effect of membrane modification by the addition of MWCNTs-IL nanocomposite was assessed first by determining the electrode response in $\mathrm{Cu}\left(\mathrm{NO}_{3}\right)_{2}$ solutions at concentrations ranging from $1 \times 10^{-8}$ to $1 \times 10^{-2} \mathrm{~mol} \mathrm{~L}^{-1}$. The obtained calibration curves are shown in Figure 1 where it can be seen that electrodes with unmodified membranes showed a similar response regardless of the kind of contact. The classic electrode $1^{*}$ was characterized by a slightly higher characteristic slope of $27.5 \mathrm{mV} /$ decade compared to electrode 1 with the same membrane but without internal solution, the slope of which was $26.7 \mathrm{mV} /$ decade. On the other hand, electrode 1 showed a slightly lower detection limit of $4.4 \times 10^{-7} \mathrm{~mol} \mathrm{~L}^{-1}$ compared to the classic electrode $1^{*}\left(5.5 \times 10^{-7} \mathrm{~mol} \mathrm{~L}^{-1}\right)$. This effect is well known for electrodes without an internal solution. The improvement in the detection limit is achieved due to the elimination of transmembrane ion fluxes [33].

The modified electrodes were characterized by a wider measuring range and lower detection limit compared to unmodified electrode 1 and classical electrode $1^{*}$ with internal solution. A gradual improvement in the electrode response can be seen as the nanocomposite content in the membrane increases. The electrode exhibiting the best response was electrode 4 which contained $6 \%$ nanocomposite in the membrane. The calibration curve of this electrode had a linear course over the widest concentration range of $1 \times 10^{-7}-1 \times 10^{-2} \mathrm{~mol} \mathrm{~L}^{-1}$ with a slope of $29.8 \mathrm{mV} /$ decade. This electrode was characterized by the lowest limit of detection $3.3 \times 10^{-8} \mathrm{~mol} \mathrm{~L}^{-1}$. Electrodes with lower composite content exhibited higher detection limits of $3.7 \times 10^{-7} \mathrm{~mol} \mathrm{~L}^{-1}$ (electrode 2) and $1.0 \times 10^{-7} \mathrm{~mol} \mathrm{~L}^{-1}$ (electrode 3). The range of linear response of these electrodes was also shorter compared to electrode 4 and the slope was close to the Nernstian one, at $28.3 \mathrm{mV} /$ decade and $28.8 \mathrm{mV} /$ decade for electrodes 2 and 3, respectively. Electrode 5, with the highest nanocomposite content $(8 \%)$, tended to have a super Nernstian response at 
lower concentrations, and the linear range of the calibration curve was shortened. As a result, the detection limit of this electrode deteriorated to $6.6 \times 10^{-6} \mathrm{~mol} \mathrm{~L}^{-1}$.

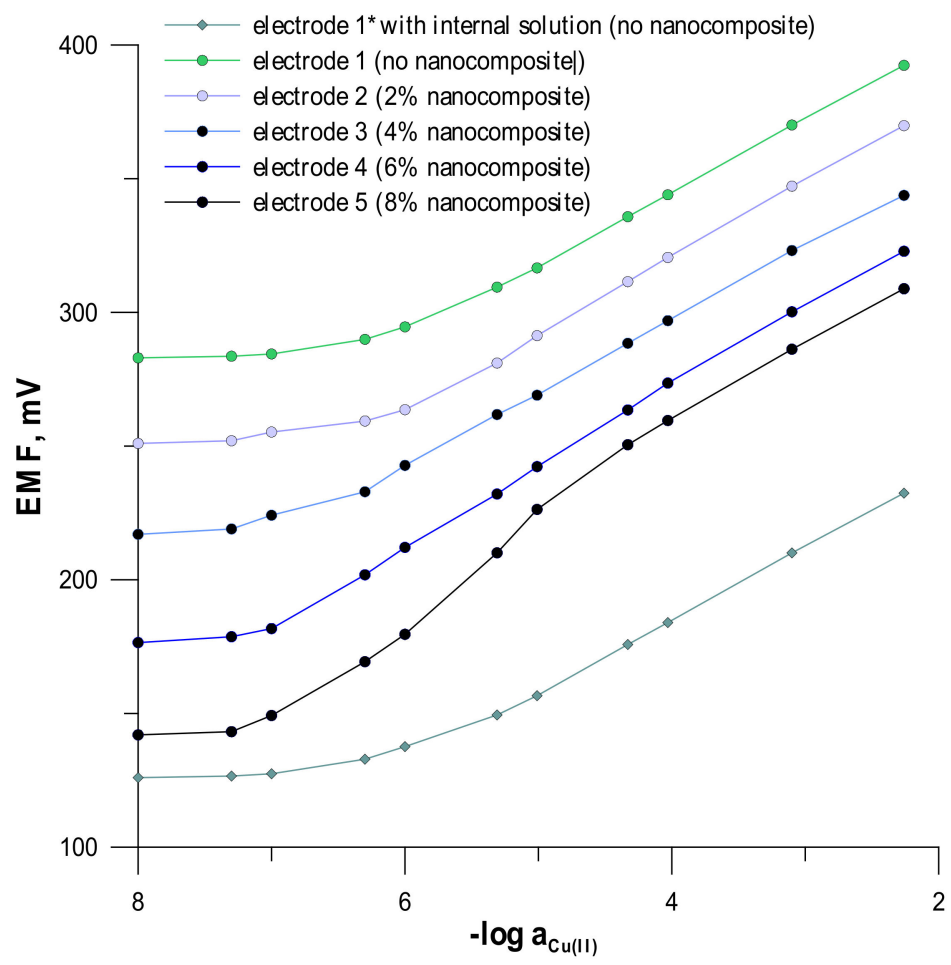

Figure 1. Calibration curves of studied electrodes.

Differences in the properties of the electrodes are due to differences in the composition of the membrane. The enrichment of the membrane with nanocomposite lowers its resistance and increases its lipophilic character. As the nanocomposite content in the membrane increases, its extraction capacity increases and the transport of $\mathrm{Cu}$ ions from the water phase to the membrane phase is more efficient.

The improvement in the electrode response is clearly revealed in the dynamic response, an example of which for electrodes 1 and 4 is shown in Figure 2. There is an evident difference in the potential stability and range of linearity for the modified electrode.

Taking into account the analytical parameters of the electrodes, such as the linear range of calibration curve, the slope of the characteristic and the limit of detection, electrode 4 was chosen for further studies. In parallel, an unmodified electrode 1 was also tested for comparison.

\subsection{Potential Stability and Reversibility}

The fully conditioned electrodes were tested to evaluate parameters such as the stability and reversibility of the potential. These parameters are important in terms of the practical application of the electrodes and have a significant influence on the accuracy of determinations and analysis time. Short term potential stability was observed during $3 \mathrm{~h}$ measurement in the $0.01 \mathrm{~mol} \mathrm{~L}^{-1} \mathrm{Cu}\left(\mathrm{NO}_{3}\right)_{2}$ solution. On the basis of total potential change, the potential drift of studied electrodes was calculated from dependence $\Delta \mathrm{E} / \Delta \mathrm{t}$. As expected, after the introduction of the MWCNTs-IL nanocomposite into the membrane phase, the stability of the electrode potential was significantly improved (Figure 3 ). The potential drift determined for electrode $4(0.046 \mathrm{mV} / \mathrm{min})$ was much smaller than the potential drift of electrode $1(0.16 \mathrm{mV} / \mathrm{min})$ without membrane modification. 


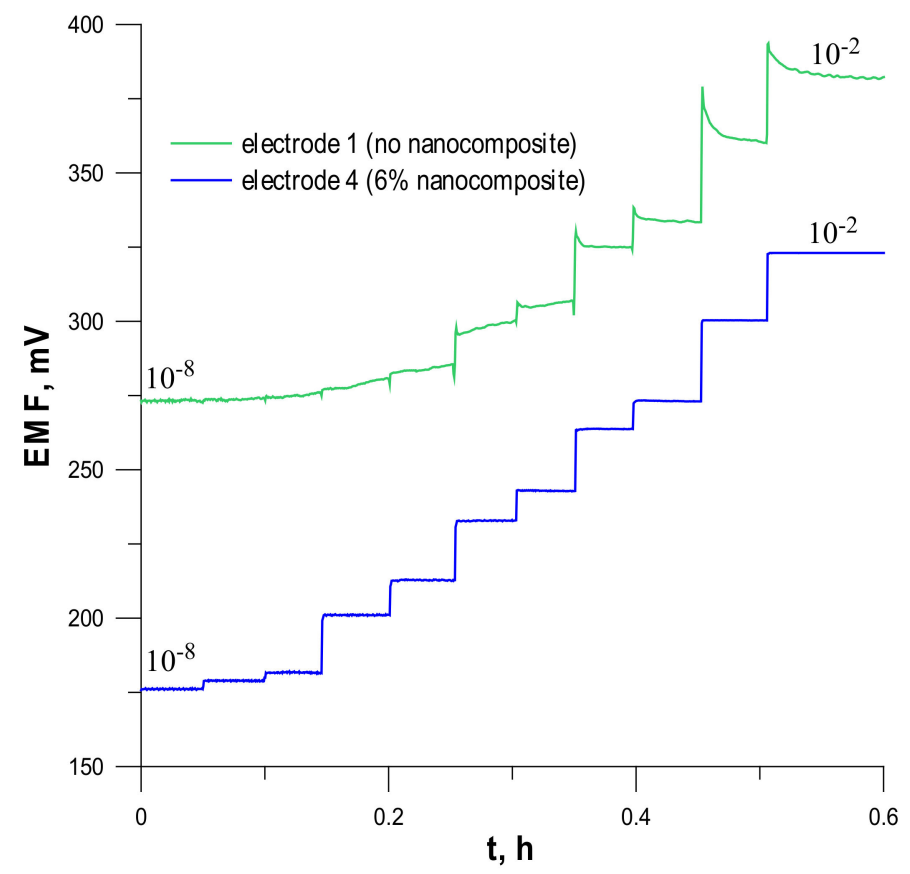

Figure 2. Potentiometric dynamic response for tested unmodified electrode 1 and electrode 4.

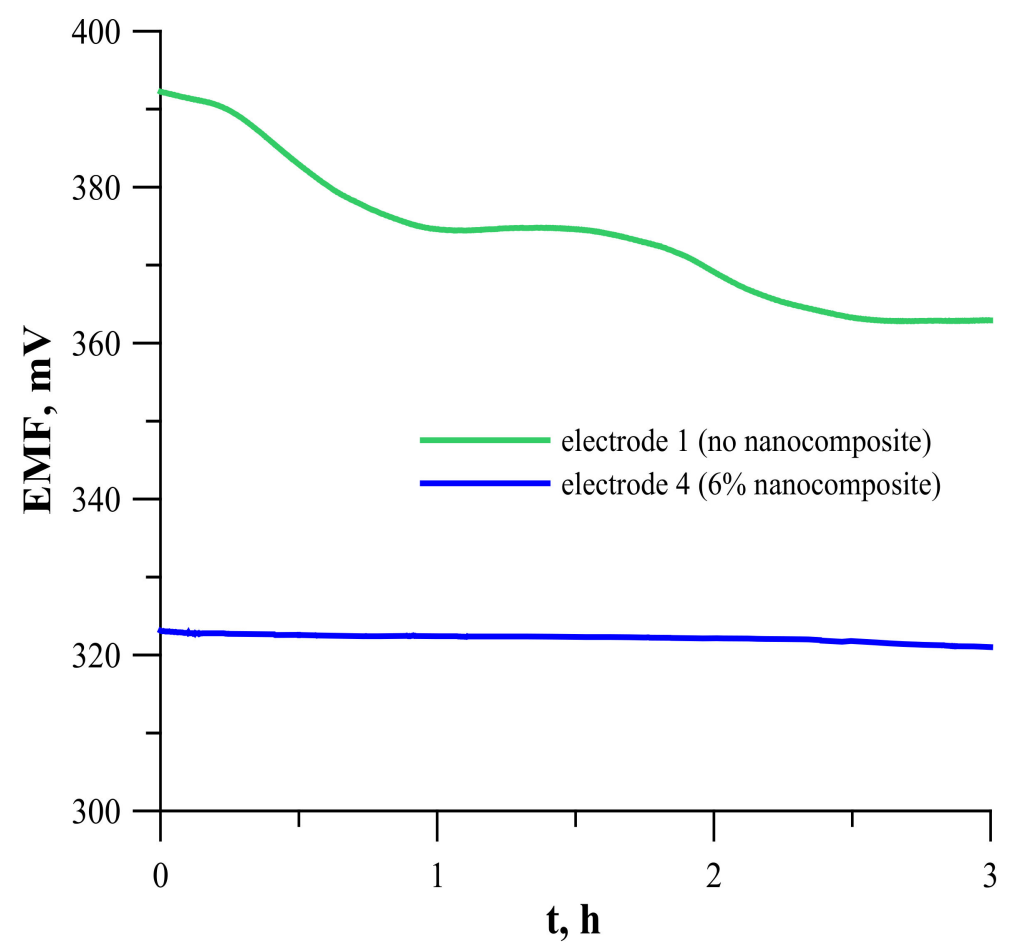

Figure 3. Comparison of potential stability of nanocomposite-based electrode 4 and unmodified electrode 1.

The improved potential stability also results in a better potential reversibility. This parameter was studied by potential measurements repetitively in $\mathrm{Cu}\left(\mathrm{NO}_{3}\right)_{2}$ solutions with the concentrations: $1 \times 10^{-5}$ and $1 \times 10^{-4} \mathrm{~mol} \mathrm{~L}^{-1}$. Time-dependent potential traces during this experiment for modified electrode 4 and unmodified electrode 1 are shown in Figure 4 where it can be seen that the potential of the modified electrode was fully reversible in contrast to the unmodified one. 


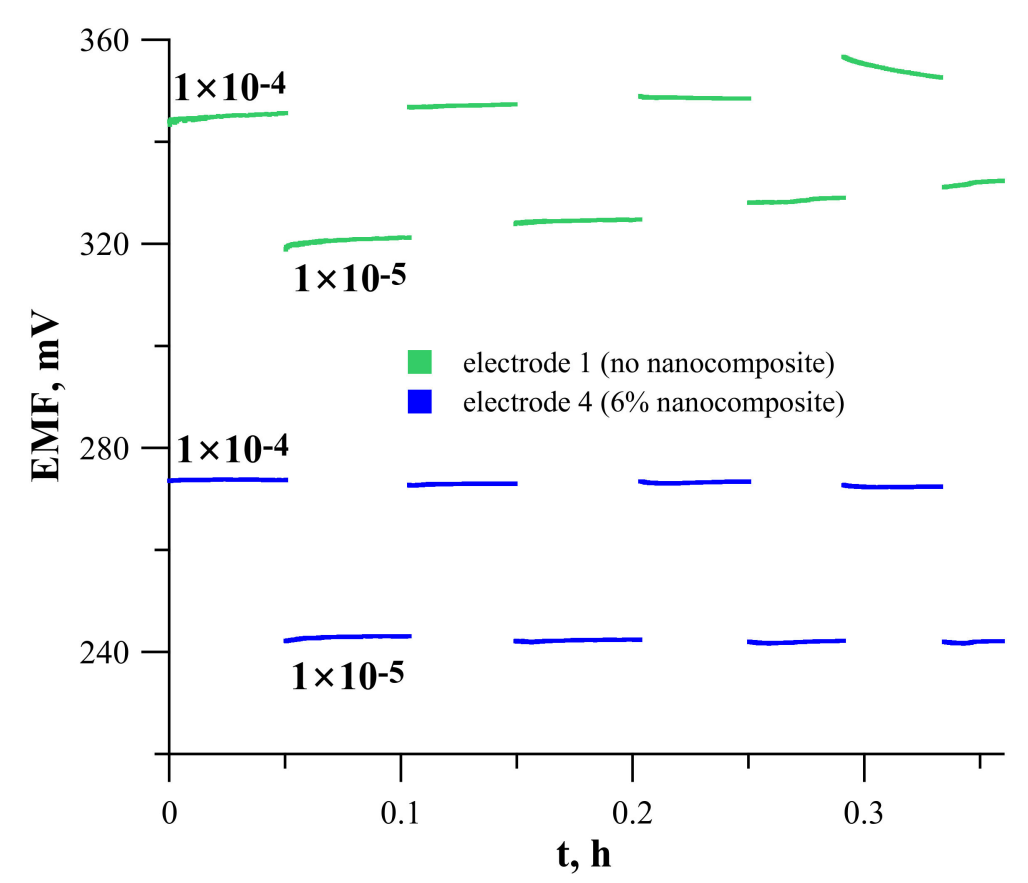

Figure 4. Potential reversibility determined in $1 \times 10^{-4}$ and $1 \times 10^{-5} \mathrm{~mol} \mathrm{~L}^{-1} \mathrm{Cu}\left(\mathrm{NO}_{3}\right)_{2}$ solution.

\subsection{Dependence of Electrode Potential on $\mathrm{pH}$}

The influence of the $\mathrm{pH}$ on the response of the studied electrode was investigated using $1 \times 10^{-4} \mathrm{~mol} \mathrm{~L}^{-1} \mathrm{Cu}\left(\mathrm{NO}_{3}\right)_{2}$ solution over the $\mathrm{pH}$ range 2.0-8.0. The $\mathrm{pH}$ was adjusted using $\mathrm{HNO}_{3}$ or $\mathrm{NaOH}$ solutions as additives and the working $\mathrm{pH}$ range was determined as where the potential of the electrode was nearly constant $( \pm 2 \mathrm{mV})$ (Figure 5). Based on this analysis, the working $\mathrm{pH}$ range was 5.0-6.0 and 2.5-6.0 for electrode 1 and electrode 4, respectively. In both cases, a gradual decrease in the potential at higher $\mathrm{pH}$ values was detected. It can be attributed to the formation of some hydroxy complexes of $\mathrm{Cu}^{2+}$ in solution. The $\mathrm{pH}$ ranges of the studied electrodes differ within acidic solutions. In this region, the change in potential is due to the interfering influence of hydrogen ions. In the case of the modified electrode, this effect is significantly reduced due to the presence of an ionic liquid in the membrane. As a result, the potential of the modified electrode does not depend on the $\mathrm{pH}$ in the broader range 2.5-6.0.

\subsection{Redox Sensitivity}

Since the presence of electron conducting nanomaterial in the membrane may induce a redox response in the ion-selective electrode, the redox sensitivity test was performed. Measurements of the electrode potential in samples with different redox potential were performed in solutions containing a pair of redox ions $\mathrm{Fe}^{2+}$ and $\mathrm{Fe}^{3+}\left(\mathrm{FeSO}_{4}\right.$ and $\left.\mathrm{Fe}_{2}\left(\mathrm{SO}_{4}\right)_{2}\right)$ in the constant ionic background of $10^{-3} \mathrm{~mol} \mathrm{~L}^{-1} \mathrm{Cu}\left(\mathrm{NO}_{3}\right)_{2}\left(\log \mathrm{Fe}^{2+} / \mathrm{Fe}^{3+}\right.$ ratio: $-1 ;-0.7$; $0 ; 0.7$ and 1) (Figure 6). The potential of the electrodes did not change much despite the change in solutions, so it was found that they are not sensitive to this type of environmental changes.

\subsection{Influence of the Presence of Gases}

Due to the willingness to use the described electrodes for testing environmental samples, it was considered important to check whether the presence of gases in water samples will affect the effectiveness and quality of copper ions determinations. For this purpose, the electrode potential was measured in a main ion solution of $10^{-3} \mathrm{~mol} \mathrm{~L}^{-1}$ previously left at room temperature in order to saturate $\mathrm{CO}_{2}$ and $\mathrm{O}_{2}$ from the air for half an hour. $\mathrm{N}_{2}$ was then passed through the solution to get rid of $\mathrm{CO}_{2}$ and $\mathrm{O}_{2}$, and the electrode potential was measured again for half an hour. The obtained relation is shown in Figure 7. 
The potential value was almost constant for the modified electrode, therefore it can be concluded that the presence of gases in the sample does not affect the operation of the proposed electrode. In the case of unmodified electrode 1, potential drift was observed both in the presence and absence of $\mathrm{CO}_{2}$ and $\mathrm{O}_{2}$ in the solution. This was probably due to a water layer forming between the inner electrode surface and the membrane, which was confirmed by a water layer test.

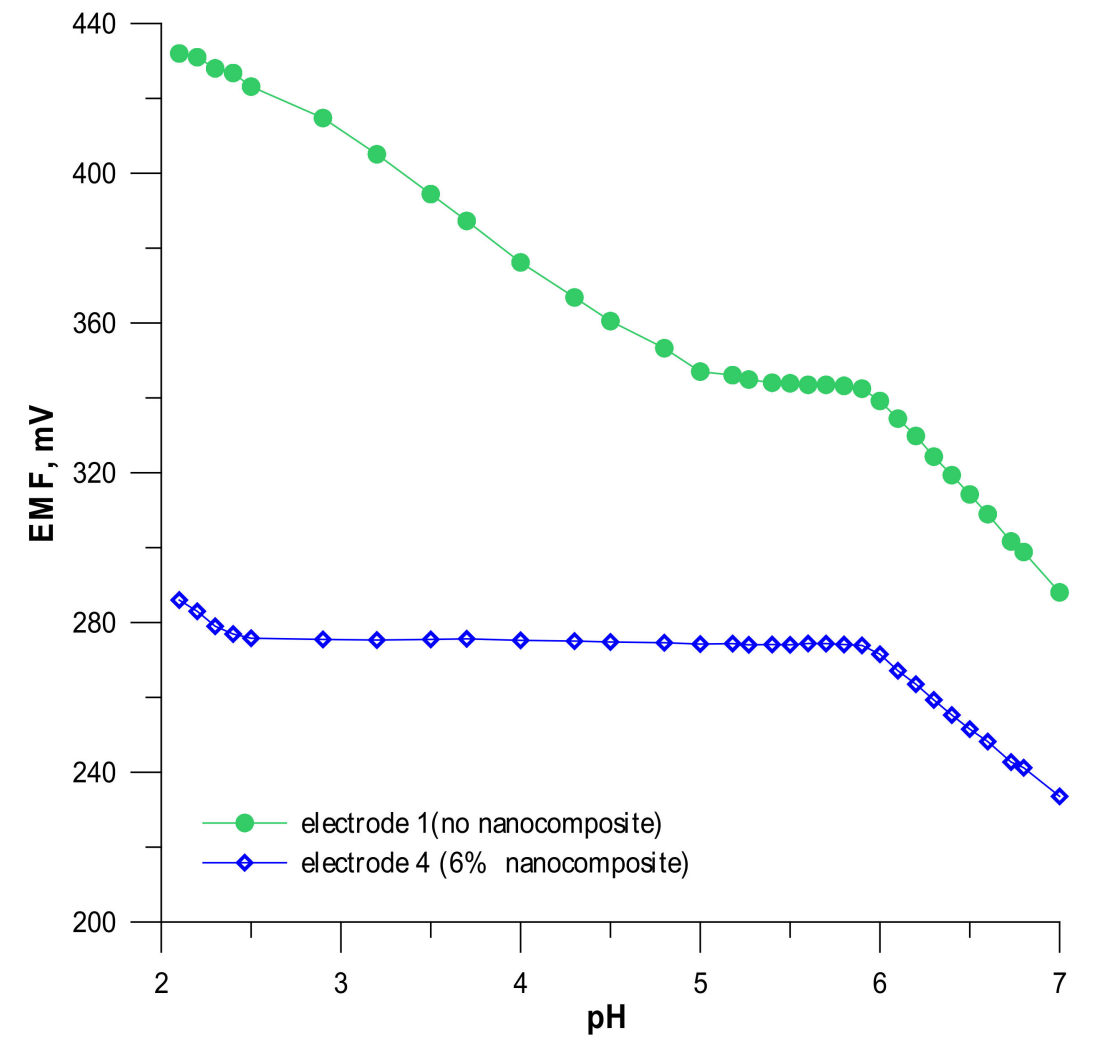

Figure 5. Dependence of electrode potential on $\mathrm{pH}$.

\subsection{Water Layer Test}

In order for ion-selective electrodes to function properly, they should meet a number of requirements. For ion-selective electrodes with solid contact, in addition to the basic parameters, such as a wide range of linearity, low detection limits and very good selectivity of sensors, resistance to changes in external conditions is also very important (e.g., the previously described sensitivity to changes in $\mathrm{pH}$ and redox potential of solutions and the presence of gases in samples) and to maintain the appropriate stability and reversibility of the sensors' potential. It has been confirmed that a thin water layer may form between the solid contact material and the ion selective membrane, the presence of which is undesirable, mainly due to the electrode potential changes it can cause [34]. A water layer test was performed following the procedure described by Pretch et al. [35]. The electrodes were immersed in a solution of $\mathrm{Cu}\left(\mathrm{NO}_{3}\right)_{2}$ with a concentration of $1 \times 10^{-2} \mathrm{~mol} \mathrm{~L}^{-1}$ for $24 \mathrm{~h}$. They were then transferred to a solution containing the salt of the interfering ion $\left(\mathrm{Zn}\left(\mathrm{NO}_{3}\right)_{2}\right)$ at the same concentration for about $3 \mathrm{~h}$, and after this time were returned to the main ion solution again. Figure 8 shows the water layer test for electrode 4 with $6 \%$ nanocomposite in the membrane and for the unmodified electrode 1. In the potential time-traces recorded for the nanocomposite-based electrode, no essential potential drift was observed after replacing the main ion solution to the interfering ion solution and after the reverse change. In the case of an unmodified electrode, a significant positive potential drift was observed first, followed by a negative one. Such results give us information that the modified 
electrode was resistant to the formation of a water layer. It was achieved by the presence in the membrane a highly lipophilic MWCNTs-BMImPF 6 nanocomposite.

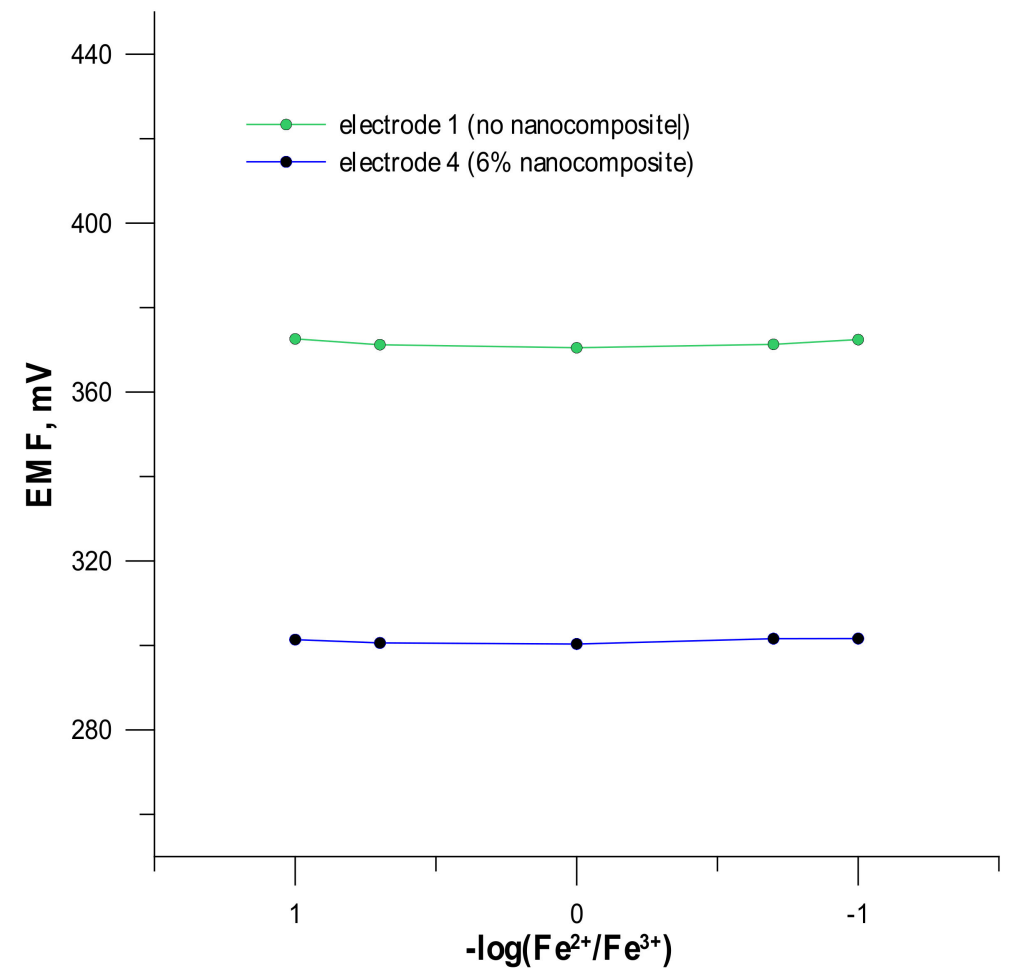

Figure 6. Redox sensitivity test for electrode 1 and modified electrode 4 .

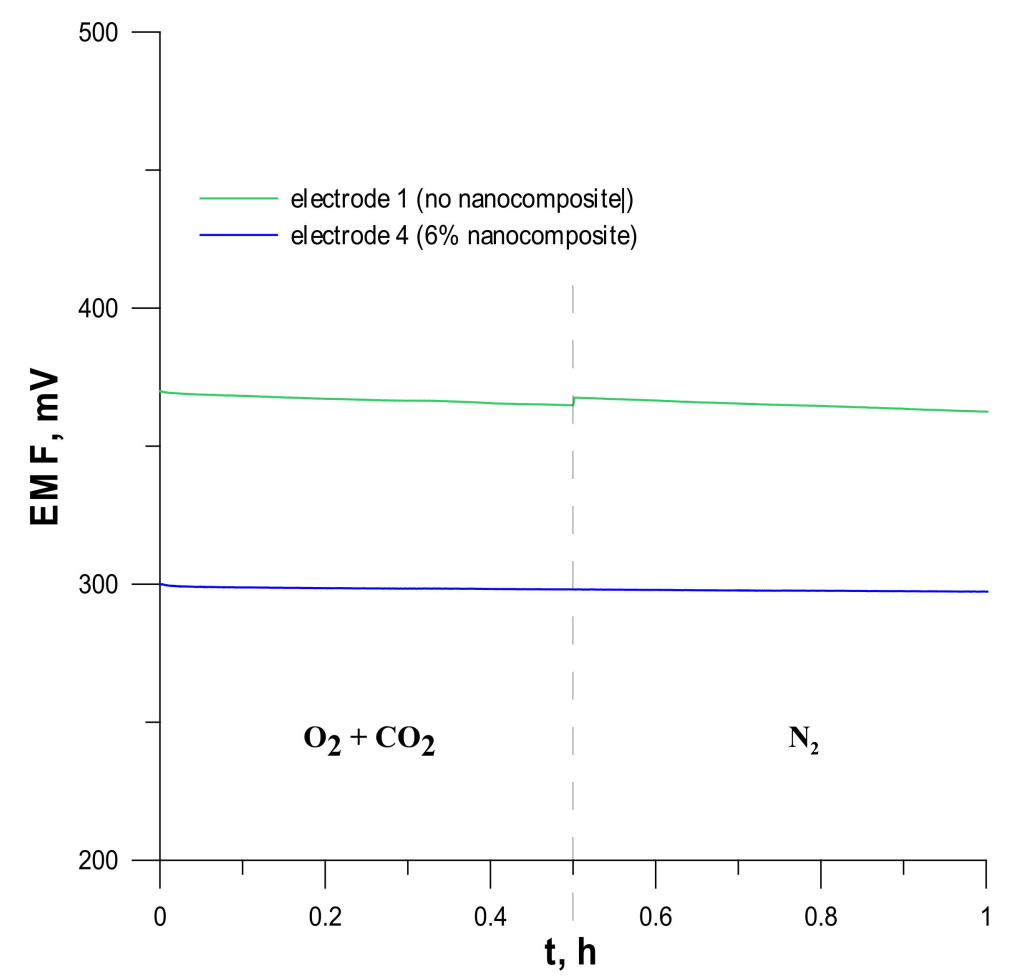

Figure 7. Influence of the presence of gases on the potential of the electrodes. 


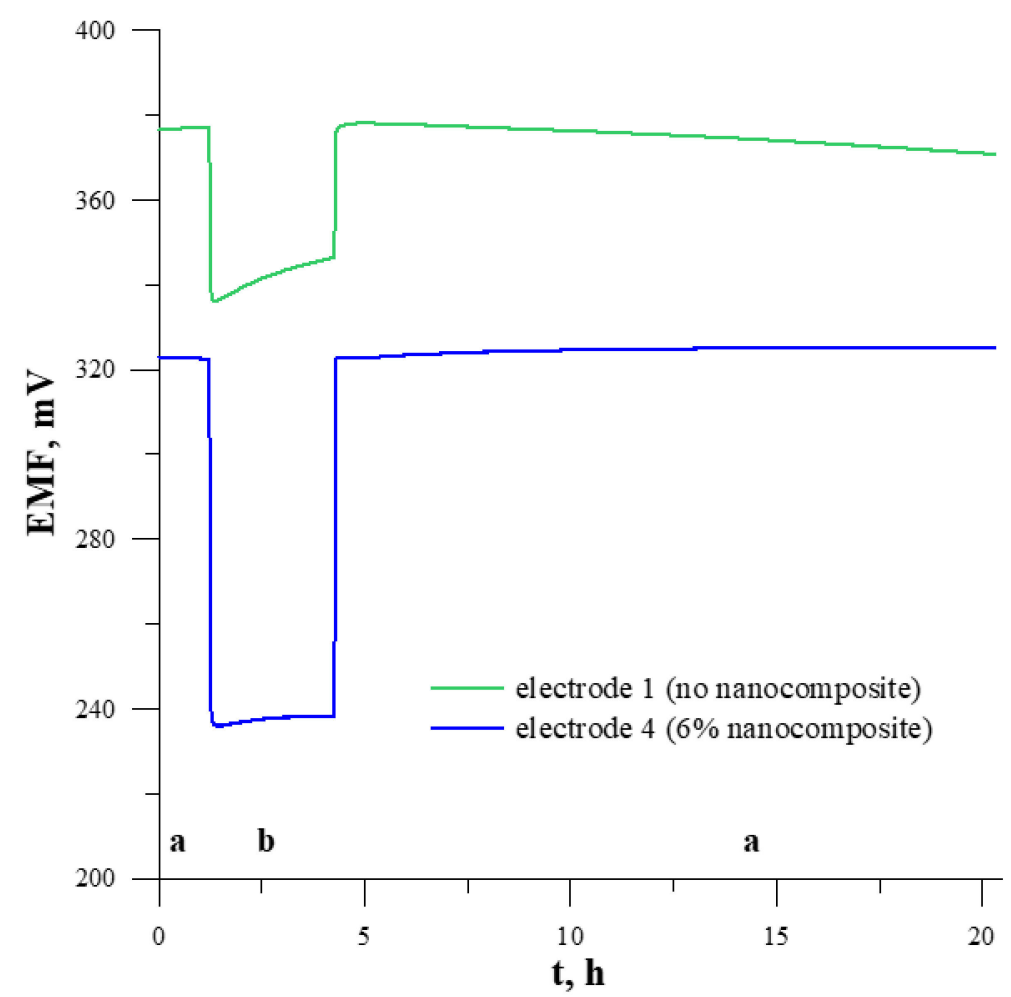

Figure 8. Water layer test of electrode 1 and 4 determined in $1 \times 10^{-2} \mathrm{~mol} \mathrm{~L}^{-1} \mathrm{Cu}\left(\mathrm{NO}_{3}\right)_{2}$ (a) and $1 \times 10^{-2} \mathrm{~mol} \mathrm{~L}^{-1} \mathrm{Zn}\left(\mathrm{NO}_{3}\right)_{2}$ (b).

\subsection{Selectivity}

One of the most important parameters of ion-selective electrodes is their selectivity, the numerical measure of which are the selectivity coefficients. The selectivity coefficient values were determined by the separate solution method (by extrapolating the response functions to $a_{i}=a_{j}=1 \mathrm{~mol} \mathrm{~L}^{-1}$ ) [36]. A comparison of selectivity coefficients obtained for nanocomposite-based electrode 4 and unmodified electrode 1 is presented in Figure 9, where it can be seen that the addition of $\mathrm{MWCNTs} \mathrm{BMImPF}_{6}$ nanocomposite to the membrane phase caused a noticeable improvement in the electrode selectivity. The obtained electrode was very selective to copper over all interfering ions $\left(\log \mathrm{K}^{\mathrm{pot}} \mathrm{Cu} / \mathrm{M} \leq-3\right)$ except lead, which was the most interfering ion $\left(\log \mathrm{K}^{\mathrm{pot}} \mathrm{Cd} / \mathrm{Pb} \leq-2.1\right)$. This was not overly surprising because lead is a well-known interferent in the case of copper selective electrodes $[37,38]$. The improvement of the selectivity of the nanocomposite-based electrode can be explained by the fact that the addition of the nanocomposite increases the ionic strength of the membrane and thus facilitates the selective transport of the main ion to the membrane phase.

\subsection{Life Time and Long Term Potential Stability}

The lifetime of the modified electrode was studied by its periodic recalibration in the $\mathrm{Cu}^{2+}$ copper nitrate solutions. The measurements were made 3 times a week during a period of 3 months. No significant change in the performance of the electrode was observed. Figure 10 presents the calibration curves of electrode 4 determined 1,5 and 12 weeks after preparation. Three-month-old electrodes still worked correctly, showing a slight increase in the detection limit to the value of $5.1 \times 10^{-8} \mathrm{~mol} \mathrm{~L}^{-1}$ and a small decrease in the slope of the characteristic to the value $28.6 \mathrm{mV} /$ decade. It is worth noting that the modified electrode was characterized by very good long term potential stability. The mean $\mathrm{E}^{0}$ value determined from 36 calibrations performed during the lifetime test was $393.2 \pm 6.3 \mathrm{mV}$. Such a small change in the $\mathrm{E}^{0}$ potential is a valuable feature of the electrode as it allows for its long-term use without the need for frequent recalibration. 


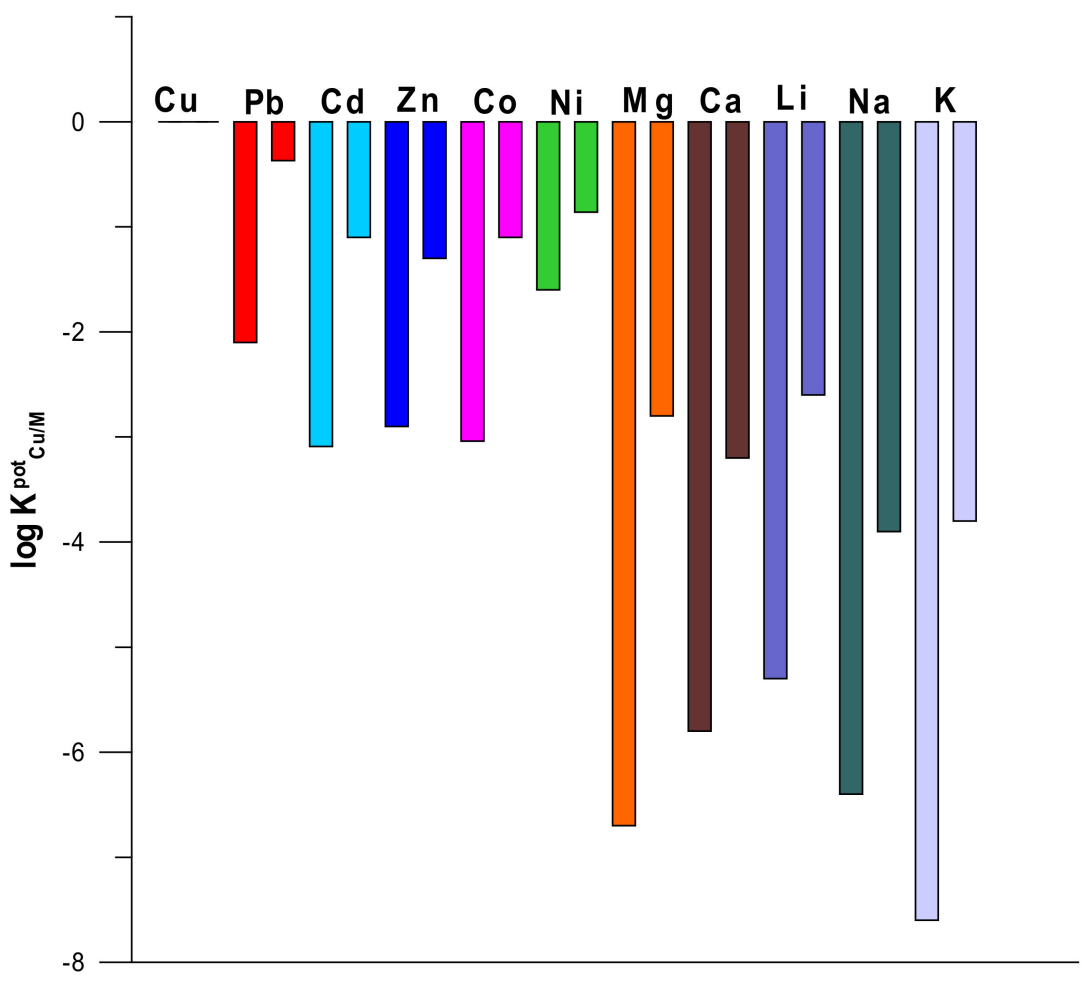

Figure 9. Comparison of selectivity coefficients of nanocomposite-based electrode 4 (1st column) and unmodified electrode 1 ( 2 nd column).

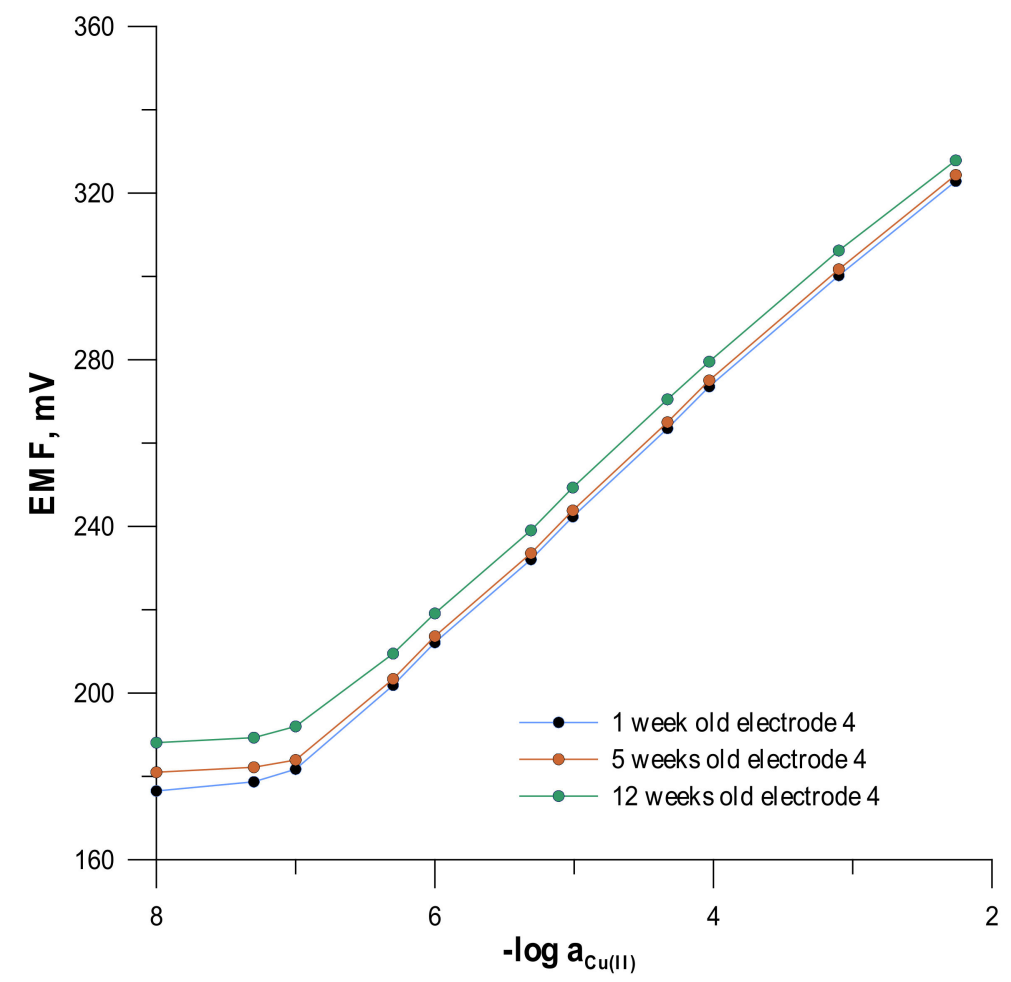

Figure 10. Change of calibration curve course in time determined for electrode 4 .

\subsection{Electrochemical Impedance Spectroscopy}

In order to study the effect of membrane modification on the electric properties of electrodes, an impedance study was carried out for fully conditioned electrodes two weeks after preparation. The obtained impedance spectra for modified electrode 4 and unmodified 
electrode 1 are shown in Figure 11. As it can be seen in this figure, both obtained impedance spectra showed a high-frequency semicircle connected to the bulk resistance $\left(R_{b}\right)$ of the ion-selective membrane and its geometric capacitance $(\mathrm{Cg})$ [39]. However, the diameter of the semicircles, which is a measure of membrane resistance, varies dramatically. The bulk membrane resistance $\left(R_{b}\right)$ determined from high frequency semicircle decreased almost ten times (from 309 to $0.36 \mathrm{k} \Omega$ ) after modification of the membrane by MWCNTs-IL nanocomposite.

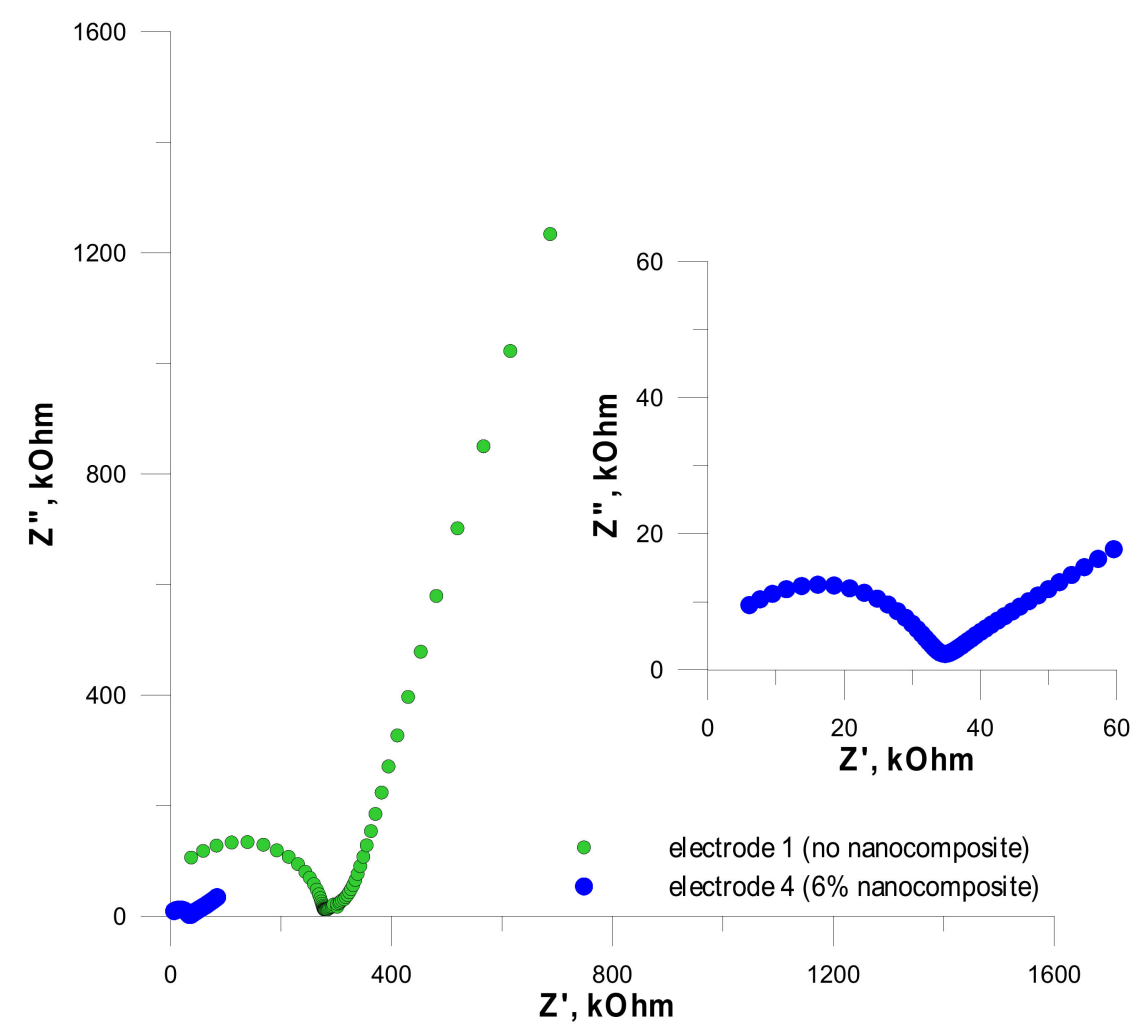

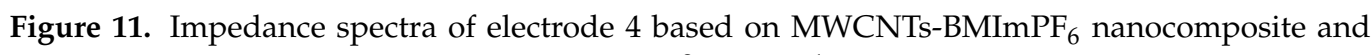
unmodified electrode 1 determined in $1 \times 10^{-2} \mathrm{~mol} \mathrm{~L}^{-1} \mathrm{Cu}\left(\mathrm{NO}_{3}\right)_{2}$ solution. Frequency range $0.1-100 \mathrm{kHz}$, amplitude $10 \mathrm{mV}$.

The second section of the impedance spectra determined for low frequencies is connected with the double layer capacitance in parallel with a charge-transfer resistance at the interface between the inner electrode and the ion-selective membrane [40]. The lowfrequency branch in the impedance spectrum of the modified electrode was much smaller than that obtained for the unmodified one. The low-frequency capacitance was calculated from the low frequency limit using the following expression $C_{1 f}=1 /\left(2 \pi f Z^{\prime \prime}\right)$ [41], where $\mathrm{f}=0.1 \mathrm{~Hz}$ was $45.7 \mu \mathrm{F}$ for electrode 4 and $1.29 \mu \mathrm{F}$ for electrode 1 . These results indicate the largest capacitance and faster diffusion processes in electrode 4 containing MWCNTs-IL nanocomposite in the membrane. The reduction in the membrane resistance and the facilitated charge transfer at the interface contribute to the improvement of the analytical parameters of the electrode, especially the improvement of the stability and the reversibility of the potential.

\subsection{Analytical Application}

The usefulness of the proposed electrode 4 in the analysis of real samples was assessed by measuring the content of copper in certified reference material SPS-WW1 Batch 111 Waste Water. This sample was analyzed without any pretreatment directly in the form in which it had been purchased after two times dilution and addition of $0.1 \mathrm{~mol} \mathrm{~L}^{-1} \mathrm{NaOH}$ to neutralize $\mathrm{HNO}_{3}$ to reach a stable $\mathrm{pH}$ of 4.5. The obtained results from five measurements 
$(n=5)$ showed that the certified value $\left(400 \pm 2 \mu \mathrm{g} \mathrm{L}^{-1}\right)$ and the value obtained by the proposed electrode $\left(412 \pm 14 \mu \mathrm{g} \mathrm{L}^{-1}\right)$ were in good agreement. Furthermore, the electrode was used for the determination of copper in river water samples. River water was collected from local river, Czerniejówka. Water samples were acidified with $\mathrm{HNO}_{3}$ to reach a stable $\mathrm{pH}$ of 4.5. Samples were spiked with $\mathrm{Cu}$ (II) ions to obtain final concentrations of $3 \times 10^{-7}$, $5 \times 10^{-7}$ and $1 \times 10^{-6} \mathrm{~mol} \mathrm{~L}^{-1}$, in order to recover measurements. The data obtained for the samples and the corresponding spiked ones are summarized in Table 1. As it can be seen, the results of the determination of copper in all cases correspond to each other well, which confirms the possibility of employing the proposed all solid-state electrode for the monitoring of copper in water samples.

Table 1. Results of copper determination in river water samples using proposed copper electrode 4.

\begin{tabular}{|c|c|c|c|}
\hline Sample & Added Copper, $\mu \mathrm{g} \mathrm{L}^{-1}$ & Found Copper by ISE, $\mu g \mathrm{~L}^{-1}$ a & Recovery, \% \\
\hline \multirow{4}{*}{ River water } & unspiked & $13.6 \pm 0.6$ & - \\
\hline & 19.2 & $33.1 \pm 1.1$ & 101.5 \\
\hline & 32 & $44.8 \pm 2.7$ & 97.7 \\
\hline & 64 & $78.1 \pm 3.1$ & 100.7 \\
\hline
\end{tabular}

\section{Conclusions}

As a result of the research, a new all solid-state copper ion-selective electrode was obtained, simple both in design and operation. The electrode obtained as a result of the membrane modification by MWCNTs-IL nanocomposite shows better selectivity than the electrode with an unmodified membrane, with a detection limit an order of magnitude lower, and a wider measuring range. Moreover, its potential is not dependent on $\mathrm{pH}$ over a much wider $\mathrm{pH}$ range. The addition of a nanocomposite to the ion-sensitive membrane also caused a noticeable reduction in the membrane resistance and an increase in capacity, which results in better potential stability.

Author Contributions: K.P.: conceptualization, methodology, investigation, data curation, writingoriginal draft preparation; C.W.: conceptualization, writing-review and editing, supervision; M.G.: validation, formal analysis. All authors have read and agreed to the published version of the manuscript.

Funding: This research received no external funding.

Institutional Review Board Statement: Not applicable.

Informed Consent Statement: Not applicable.

Data Availability Statement: Not applicable.

Conflicts of Interest: The authors declare no conflict of interest.

\section{References}

1. Stern, B.R.; Solioz, M.; Krewski, D.; Aggett, P.; Aw, T.-C.; Baker, S.; Crump, K.; Dourson, M.; Haber, L.; Hertzberg, R.; et al. Copper and human health: Biochemistry, genetics, and strategies for modeling dose-response relationships. J. Toxicol. Environ. Health Part B 2007, 10, 157-222. [CrossRef]

2. Wardak, C.; Grabarczyk, M. Analytical application of solid contact ion-selective electrodes for determination of copper and nitrate in various food products and drinking water. J. Environ. Sci. Health Part B 2016, 51, 519-524. [CrossRef] [PubMed]

3. Bost, M.; Houdart, S.; Oberli, M.; Kalonji, E.; Huneau, J.-F.; Margaritis, I. Dietary copper and human health: Current evidence and unresolved issues. J. Trace Elements Med. Biol. 2016, 35, 107-115. [CrossRef] [PubMed]

4. Kaplan, J.H.; Maryon, E.B. How mammalian cells acquire copper: An essential but potentially toxic metal. Biophys. J. 2016, 110, 7-13. [CrossRef]

5. Gupta, V.K.; Ganjali, M.R.; Norouzi, P.; Khani, H.; Nayak, A.; Agarwal, S. Electrochemical analysis of some toxic metals by ion-selective electrodes. Crit. Rev. Anal. Chem. 2011, 41, 282-313. [CrossRef]

6. Huang, M.-R.; Gu, G.-L.; Ding, Y.-B.; Fu, X.-T.; Li, R.-G. Advanced solid-contact ion selective electrode based on electrically conducting polymers. Chin. J. Anal. Chem. 2012, 40, 1454-1460. [CrossRef] 
7. Bieg, C.; Fuchsberger, K.; Stelzle, M. Introduction to polymer-based solid-contact ion-selective electrodes-Basic concepts, practical considerations, and current research topics. Anal. Bioanal. Chem. 2017, 409, 45-61. [CrossRef] [PubMed]

8. Hu, J.; Stein, A.; Bühlmann, P. Rational design of all-solid-state ion-selective electrodes and reference electrodes. TrAC Trends Anal. Chem. 2016, 76, 102-114. [CrossRef]

9. Tutulea-Anastasiu, M.D.; Wilson, D.; Del Valle, M.; Schreiner, C.M.; Creţescu, I. A solid-contact ion selective electrode for copper(ii) using a succinimide derivative as ionophore. Sensors 2013, 13, 4367-4377. [CrossRef]

10. Kisiel, A.; Michalska, A.; Maksymiuk, K. Rectifying effect for ion-selective electrodes with conducting polymer solid contact. Synth. Met. 2018, 246, 246-253. [CrossRef]

11. Yu, S.-Y.; Li, Y.-C.; Xiong, T.; Yuan, Q.; Liu, Y.-M.; Yuan, Z.-Y.; Xiao, Y. A ladder conjugated polymer transducer for solid-contact $\mathrm{Cu}^{2+}$-selective electrodes. Chin. Chem. Lett. 2013, 25, 364-366. [CrossRef]

12. Gyurcsányi, R.E. Microfabricated ISEs: Critical comparison of inherently conducting polymer and hydrogel based inner contacts. Talanta 2004, 63, 89-99. [CrossRef]

13. Fibbioli, M.; Enger, O.; Diederich, F.; Pretsch, E.; Bandyopadhyay, K.; Liu, S.-G.; Echegoyen, L.; Bühlmann, P. Redox-active self-assembled monolayers as novel solid contacts for ion-selective electrodes. Chem. Commun. 2000, 339-340. [CrossRef]

14. Liang, R.; Yin, T.; Qin, W. A simple approach for fabricating solid-contact ion-selective electrodes using nanomaterials as transducers. Anal. Chim. Acta 2015, 853, 291-296. [CrossRef] [PubMed]

15. Parra, E.J.; Crespo, G.A.; Riu, J.; Ruiz, A.; Rius, F.X. Ion-selective electrodes using multi-walled carbon nanotubes as ion-to-electron transducers for the detection of perchlorate. Analyst 2009, 134, 1905-1910. [CrossRef] [PubMed]

16. Hu, J.; Zou, X.U.; Stein, A.; Bühlmann, P. Ion-selective electrodes with colloid-imprinted mesoporous carbon as solid contact. Anal. Chem. 2014, 86, 7111-7118. [CrossRef]

17. Lai, C.-Z.; Joyer, M.M.; Fierke, M.A.; Petkovich, N.D.; Stein, A.; Bühlmann, P. Subnanomolar detection limit application of ion-selective electrodes with three-dimensionally ordered macroporous (3DOM) carbon solid contacts. J. Solid State Electrochem. 2009, 13, 123-128. [CrossRef]

18. Paczosa-Bator, B. All-solid-state selective electrodes using carbon black. Talanta 2012, 93, 424-427. [CrossRef] [PubMed]

19. Jaworska, E.; Wójcik, M.; Kisiel, A.; Mieczkowski, J.; Michalska, A. Gold nanoparticles solid contact for ion-selective electrodes of highly stable potential readings. Talanta 2011, 85, 1986-1989. [CrossRef]

20. Paczosa-Bator, B.; Piech, R.; Cabaj, L.; Skupień, K. Platinum nanoparticles intermediate layer in solid-state selective elec-trodes. Analyst 2012, 137, 5272-5277. [CrossRef]

21. Liu, Y.; Liu, Y.; Yan, R.; Gao, Y.; Wang, P. Electrochimica acta bimetallic AuCu nanoparticles coupled with multi-walled carbon nanotubes as ion-to-electron transducers in solid-contact potentiometric sensors. Electrochim. Acta 2020, 331, 135370. [CrossRef]

22. Matzeu, G.; Zuliani, C.; Diamond, D. Electrochimica acta solid-contact ion-selective electrodes (ISEs) based on ligand functionalised gold nanoparticles. Electrochim. Acta 2015, 159, 158-165. [CrossRef]

23. Papp, S.; Kozma, J.; Lindfors, T.; Gyurcsányi, R.E. Lipophilic multi-walled carbon nanotube-based solid contact potassium ion-selective electrodes with reproducible standard potentials. A comparative study. Electroanalysis 2020, 32, 867-873. [CrossRef]

24. Jaworska, E.; Maksymiuk, K.; Michalska, A. Optimizing carbon nanotubes dispersing agents from the point of view of ionselective membrane based sensors performance-Introducing carboxymethylcellulose as dispersing agent for carbon nanotubes based solid contacts. Electroanalysis 2015, 28, 947-953. [CrossRef]

25. Wardak, C. Ionic liquids as new lipophilic additives to the membrane of lead ion-selective electrodes with solid contact. Int. J. Environ. Anal. Chem. 2009, 89, 735-748. [CrossRef]

26. Wardak, C.; Lenik, J. Application of ionic liquid to the construction of Cu (II) ion-selective electrode with solid contact. Sens. Actuators B Chem. 2013, 189, 52-59. [CrossRef]

27. Huang, H.-L. Extraction of copper species from the nanoporous sorbent with an ionic liquid. J. Mol. Liq. 2017, 230, 24-27. [CrossRef]

28. Arain, S.A.; Kazi, T.G.; Afridi, H.I.; Arain, M.S.; Panhwar, A.H.; Khan, N.; Baig, J.A.; Shah, F. A new dispersive liquid-liquid microextraction using ionic liquid based microemulsion coupled with cloud point extraction for determination of copper in serum and water samples. Ecotoxicol. Environ. Saf. 2016, 126, 186-192. [CrossRef] [PubMed]

29. Wardak, C. A Comparative study of cadmium ion-selective electrodes with solid and liquid inner contact. Electroanalysis 2012, 24, 85-90. [CrossRef]

30. Wardak, C. Solid contact cadmium ion-selective electrode based on ionic liquid and carbon nanotubes. Sens. Actuators B Chem. 2015, 209, 131-137. [CrossRef]

31. Zhao, Y.; Gao, Y.; Zhan, D.; Liu, H.; Zhao, Q.; Kou, Y.; Shao, Y.; Li, M.; Zhuang, Q.; Zhu, Z. Selective detection of dopamine in the presence of ascorbic acid and uric acid by a carbon nanotubes-ionic liquid gel modified electrode. Talanta 2005, 66, 51-57. [CrossRef]

32. Fukushima, T.; Aida, T. Ionic liquids for soft functional materials with carbon nanotubes. Chem. Eur. J. 2007, 13, 5048-5058. [CrossRef]

33. Sutter, J.; Lindner, E.; Gyurcsányi, R.E.; Pretsch, E. A polypyrrole-based solid-contact $\mathrm{Pb}^{2+}$-selective PVC-membrane electrode with a nanomolar detection limit. Anal. Bioanal. Chem. 2004, 380, 7-14. [CrossRef]

34. Lindner, E.; Gyurcsányi, R.E. Quality control criteria for solid-contact, solvent polymeric membrane ion-selective electrodes. J. Solid State Electrochem. 2009, 13, 51-68. [CrossRef] 
35. Fibbioli, M.; Morf, W.E.; Badertscher, M.; De Rooij, N.F.; Pretsch, E. Potential drifts of solid-contacted ion-selective electrodes due to zero-current ion fluxes through the sensor membrane. Electroanalysis 2000, 12, 1286-1292. [CrossRef]

36. Bakker, E.; Pretsch, E.; Bühlmann, P. Selectivity of potentiometric ion sensors. Anal. Chem. 2000, 72, 1127-1133. [CrossRef] [PubMed]

37. Szigeti, Z.; Bitter, I.; Tóth, K.; Latkoczy, C.; Fliegel, D.J.; Günther, D.; Pretsch, E. A novel polymeric membrane electrode for the potentiometric analysis of $\mathrm{Cu}^{2+}$ in drinking water. Anal. Chim. Acta 2005, 532, 129-136. [CrossRef]

38. Ghaedi, M.; Montazerozohori, M.; Sahraei, R. Comparison of the influence of nanomaterials on response properties of copper selective electrodes. J. Ind. Eng. Chem. 2013, 19, 1356-1364. [CrossRef]

39. Horvai, G.; Graf, E.; Toth, K.; Pungor, E.; Buck, R.P. Plasticized poly(vinyl chloride) properties and characteristics of valinomycin electrodes. 1. High-frequency resistances and dielectric properties. Anal. Chem. 1986, 58, 2735-2740. [CrossRef]

40. Bobacka, J.; Lewenstam, A.; Ivaska, A. Electrochemical impedance spectroscopy of oxidized poly(3,4-ethylenedioxythiophene) film electrodes in aqueous solutions. J. Electroanal. Chem. 2000, 489, 17-27. [CrossRef]

41. Mousavi, Z.; Teter, A.; Lewenstam, A.; Maj-Zurawska, M.; Ivaska, A.; Bobacka, J. Comparison of multi-walled carbon nanotubes and poly(3-octylthiophene) as ion-to-electron transducers in all-solid-state potassium ion-selective electrodes. Electroanalysis 2011, 23, 1352-1358. [CrossRef] 